Saudi Journal of Oral and Dental Research

Abbreviated Key Title: Saudi J Oral Dent Res

ISSN 2518-1300 (Print) |ISSN 2518-1297 (Online)

Scholars Middle East Publishers, Dubai, United Arab Emirates

Journal homepage: https://saudijournals.com/sjodr

Review Article

\title{
Current Trends and Recent Advances in Surface Texture of Endoosseous Dental Implants: An Overview
}

Dr. Pooja Ishwarprasad Agroya, MDS $^{1 *}$, Dr. Archana Agroya, MDS $^{2}$, Dr. Godavari Deepak Nagargoje ${ }^{3}$, Dr. Nirav R $\mathrm{Shah}^{4}$, Dr. Sagar H Mohkar ${ }^{5}$, Dr. Mohammed Shammas ${ }^{6}$

${ }^{1}$ Department of Prosthodontics, Crown \& Bridge, Sri Sai College of Dental Surgery, Vikarabad, India

${ }^{2}$ Senior Lecturer, Department of Periodontology \& Implantology, Sri Sai College of Dental Surgery, Vikarabad, India

${ }^{3}$ Senior Lecturer, Department of Conservtive Dentistry \& Endodontology, Nanded Rural dental College \& Research centre, Nanded, Maharashtra

${ }^{4}$ Consultant Periodontist and Implantologist, Stat Care clinic, Ahmedabad, Gujarat India

${ }^{5}$ Reader, Conservative dentistry and endodontics, VYWS dental college and hospital Amravati, Maharashtra

${ }^{6}$ Division of Prosthodontics, Department of Oral and Maxillofacial Rehabilitation, Ibn Sina National College for Medical Studies, Jeddah, Saudi Arabia

DOI: $10.36348 /$ sjodr.2020.v05i08.009 $\quad$ | Received: 12.08.2020| Accepted: 25.08.2020 | Published: 29.08 .2020

*Corresponding author: Dr. Pooja Ishwarprasad Agroya, MDS

\section{Abstract}

This review article describes about the various surface treatments or modifications of the dental implants. Previously dental clinicians believe that osteogenic cells did not responds to the changes in the Nano structure of the dental implant surface but recent studies have shown that Osteogenic cells responds to the surface modifications or various surface modifications ${ }^{1}$. This review article describes about the Titanium dioxide Nano tube arrangement, functional peptide coatings, fluoride treatment, calcium phosphorus application, UV photo functionalization. Various studies have shown that these surface treatments increase the dental implant survival rate to $95 \%$.

Keywords: Surfate texture, implants, endoossoues, current trends.

Copyright @ 2020: This is an open-access article distributed under the terms of the Creative Commons Attribution license which permits unrestricted use, distribution, and reproduction in any medium for non-commercial use (NonCommercial, or CC-BY-NC) provided the original author and source are credited.

\section{INTRODUCTION}

Osseointegration is a essentially demarcation response to a foreign body titanium which is a immune driven type 4 hyper sensitivity reaction. Osseointeg ration plays a key role in success of dental implants [1]. Surface is important for better osseointegration of the dental implant. Titanium is a best material of choice for dental implants because of its properties like excellent biocompatibility, corrosion resistance, high strength, low modulus of elasticity and easy machinability [2]. Surface modifications of dental implant improve the wettability of the implant surface so that it improves the cell to implant adhesion, cell proliferation and osseointegration which leads to the better secondary stability of the dental implant. Recently many studies have been carried out on surface treatment commercial pure Titanium to improve the osseointegration. Initially after implant placement stability of the dental implant occurs with the friction this is called as primary stability. Primary stability decreases subsequently to implant insertion while secondary stability increases. After 2-3 weeks, the implant stability is the lowest in a phase called implant stability dip. This secondary stability occurs with the osseointegration after placement of the dental implant so for an implant success not only the primary stability but also the secondary stability also important features [3] (Figure 1). 


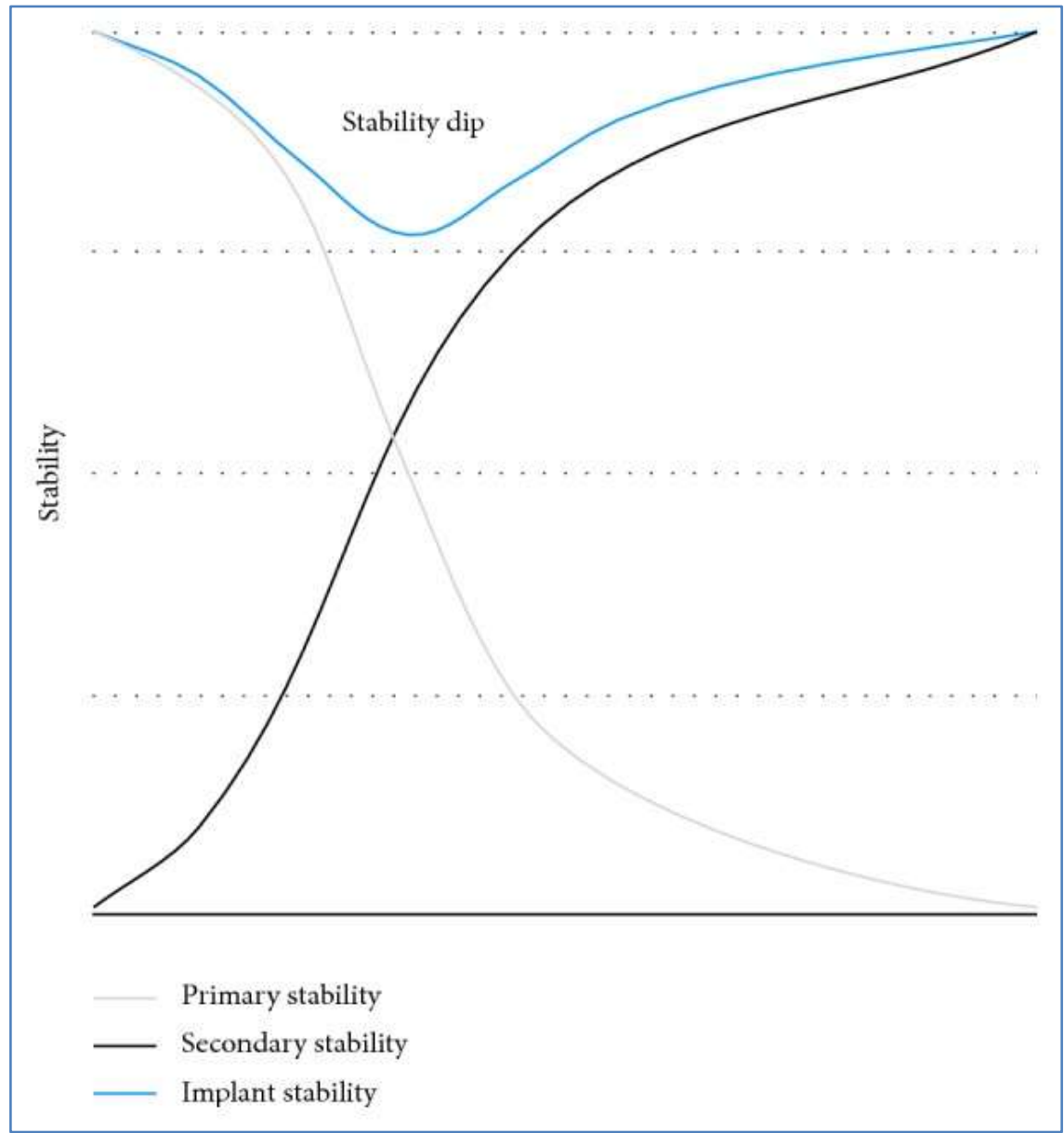

Fig-1: Figure Showing Primary Stability \& Secondary Stability Post Implant Placement

\section{Need for implant surface treatment [2]}

To increase the surface area of the dental implant, to bring better bonding between implant surface and surrounding bone, to increase surface roughness of the dental implant, to make them more passive, to remove the surface contamination

\section{According to Albrektsson \& wennerberg commercially available implants have been categorised into four types \\ 1. Smooth ( $\mathrm{sa}<0.5$ micro meters) \\ 2. Minimally rough (sa $0.5-1)$ \\ 3. Moderately rough (sa1-2) \\ 4. Rough ( $\mathrm{sa}>2)$}

Table-1: Different surface treatments classification [3]

\begin{tabular}{|l|l|}
\hline - Subtractive treatments & Additive treatments \\
\hline Machined & Anodization \\
\hline - Sandblasted & $\bullet$ Fluoride surface treatment \\
\hline • Acid-etched surface & $\bullet$ plasma spraying \\
& Ti \\
& Hydroxyapatite (HA). \\
\hline$\bullet$ Dual acid-etching & Coating sol-gel \\
\hline - Sandblasted and acid etched surface (SLA) & • Sputter deposition \\
\hline - Laser treatment & $\bullet$ Electrophoretic deposition \\
\cline { 2 - 2 } & $\bullet$ Biomimetic precipitation \\
\cline { 2 - 2 } & $\bullet$ Drugs incorporated \\
\hline
\end{tabular}

\section{Machined surface (turned surface)[4]}

The presence of crease, crinkle, and splotch by the device used for the manufacturing on the surfaces of machined implants provides mechanical interlocking. The morphology of machined implants encourages the proliferation of osteoblastic cells into the grooves and roughened surfaces on the dental implant, which is a disadvantage. The machined implant surface is considered to be minimally rough. Machined implant surfaces have SA values of 0.3-1.0 $\mu \mathrm{m}$. This feature requires a longer waiting time between surgery and implant loading. 


\section{Sand blasted surface treatment [4]}

Maximum surface roughness required to achieve affective biological response is 1.5 micrometers. In this technique implant surface blasted with ceramic particles. Surface roughness depends on the size of the ceramic particles. Other materials that are used to sand blasting the implant surface are aluminum oxide, titanium dioxide, silicon dioxide. These particles accelerate the osseointegration process when releases into the surrounding physiological environment and decreases the corrosion resistance $[5,6]$.

\section{Alkaline etching [7]}

Procedure: treatment of titanium with $4-5 \mathrm{M}$ $\mathrm{NAOH}$ at $600^{\circ} \mathrm{C}$ for $24 \mathrm{hrs}$. This procedure results in formation of sodium titanate of 1 micrometer thickness with irregular topography, if this procedure is carried out after acid etching results in increased porosity.

\section{Surface treatment by acid etching}

Acids that are used to etch the dental implant surface are $\mathrm{HCL}, \mathrm{H}_{2} \mathrm{SO}_{4}, \mathrm{HNO}_{3}$, and HF.in this procedure implant surface should be etched by immersing in to the mixture of concentrated HCL and $\mathrm{H}_{2} \mathrm{SO}_{4}$ at above $100^{\circ}$ c.this procedure is called as dual acid etching procedure[8]. It creates microoughned surface for accelerated osseointegration and it increases the osteoconductive process by attachment of fibrin, and osteigenic cells leading to bone formation on the implant microroughned surface. Another approach is fluoride treatment which leads to formation of $\mathrm{TiF}_{4}$ this accelerates the osseountegration process [7].

\section{Sla (sand blasted and acid etched surface)}

It is done by process of sand blasting with 250500 micrometers size ceramic particles and by etching the implant surface with $\mathrm{HCl}$ and $\mathrm{H}_{2} \mathrm{SO}_{4}$, this procedure results a new hydrophilic surface calls SLAactive. This SLA active creates a chemically active surface. To this anions which are taken from acids such as fluoride ions also added .Most of the studies have shown that SLA treated implants creates a greater bone contact and stability at early healing phase of 6weeks. Laser treatment: the laser ablation develops micro roughness on dental implant surface which increases the osseointegration, resistance to corrosion and a large quality of purity with a definitive roughness and compact oxide layer [7-9].

\section{Additive treatments}

Anodization: This procedure is carried out at high voltage in strong acids like $\mathrm{H}_{3} \mathrm{PO}_{4} \mathrm{HNO}_{3} \mathrm{H}_{2} \mathrm{SO}_{4}$, $\mathrm{HF}$ resulting in crystallization of surface.it leads to thickening of oxide layer to more than $1000 \mathrm{~nm}$ on implant surface. This process accelerates the osseointegration more than that of machined surfaces [10].
Fluoride treatment: Ti surface is very sensible to fluoride ions and it forms $\mathrm{TiF}$ which is soluble in nature. This process increases the osteoblastic differentiation and osseointegration. flouride ion treated implants also had a greater push out forces and showed a significantly more advanced torque removal forces in many studies[9].

\section{Roughening of implant surface by plasma spraying}

The advantage of this technique is that these layers give implants a porous surface making easy for the bone to penetrate easily. The implant rough surface within the range of 50-400micro meters. Titanium and calcium phosphate can be added by plasma spraying technique [10].

Titanium plasma spraying: titanium plasma spraying was introduced approx 35 years back. Primarily in 1970, Hahn\&Palich described micro porous nature of surface of orthopaedic implants, which was later attempted in dental implants by Schroeder et al. this procedure includes heating titanium to plasma form and spray this plasma on implant surface which can increase the apertures on implant surface by six times (30 to $50 \mu \mathrm{m}$ deep), thus enhancing micro retention. The surface area of implant after plasmaspray is around 3 times that of a machined surface [11].

\section{HA plasma spraying}

Hydroxy apatite is one of the materials that forms strong bond between titanium implant and bone, it improves the chemical and mechanical properties and increases the corrosion resistance. Plasma-spraying is a technique in which hydroxyapatite (HA) ceramic particles are injected into a plasma torch at high temperature and projected on to the surface of the titanium dental implant where they condense and fuse together, forming a film. Plasma-sprayed coatings can be deposited with a thickness ranging from a few micro meters to a few milli meters. When using this method In order to obtain mechanical retention of the coating, the surface of the titanium dental implant must be roughened by means of grit blasting [12]. The plasmaspraying method has disadvantages, however, such as the porosity of the coating and residual stress at the substrate/coating interface, as well as drastic changes in the composition and crystallinity of the initial calcium phosphate powder. Several calcium phosphate phases have been observed in plasma-sprayed HA coatings such as tricalcium phosphates, tetracalcium phosphate calcium oxide and amorphous calcium phosphate (ACP). The main disadvantage of this technique id delamination of the hydroxyl apatite layer [13]. Sol gel coated implants: this technique is straight forward and inexpensive. This technique includes homologous chemical distribution on the implant surface. The main advantage of this technique is increased toughness when compare with bioactive ceramics, biological acceptability which leads to early bone formation during healing phase and mechanical strength [13]. 
Sputter deposition: This is a process in which high energy loss are discharged in a vacuum chamber to change the surface texture of a titanium implant surface [14].

Radiofrequency sputtering: This process includes the formation of thin film o calcium phosphate coatings on dental implants. It forms strong adhesive link between titanium and calcium phosphate [13].

Magnetron sputtering: This process includes formation of the $\mathrm{TiO}_{2}$ layer at the bone and implant surface which establishes the strong bond between titanium and hydroxyl apatite layer [13].

Biomimic calcium phosphate coatings: This process implant surface will have plasma sprayed hydroxyl apatite coating which is inspired by the natural process of ion mineralisation and this contains modification like condensation of the calcium phosphate apatite crystals on the surface of the dental implants. These biomimetic coatings are more soluble in physiological fluids and resorbable by osteoclastic cells [15].

Biologically active drug incorporated dental implants: surface treatment with osteogenic and antiresorptive drugs like bisphosphonates improves the osseointegration [16].

\section{Bisphosphonates}

Bisphosphonates like pamidronate and zoledronate escalates the bone contact area but the major disadvantage of this technique will be present in the grafting anf slow discharge of drug on the surface of titanium implant [16].

\section{Simvastatin}

Increases the release of bone morphogenic protein $2 \mathrm{~m}$-rna which accelerates the bone formation. Most of the studies have shown that surface treatment with simvastatin increases the bone mineral density around the dental implant [16].

\section{Antibiotic coating}

Gentamycin with hydroxyapatite coating on dental implant surface will act like prophylactic agnt around the implant and it reduces the surgical site infection.

Tetracyclin-HCL surface treatment can be used as practical and efficient chemical method for decontamination and detoxification of harmed surface of implants [17].

\section{CONCLUSION}

Previously success rate of dental implants were more common to overcome these complications and to increase the success of the dental implants various surface modifications are introduced and still research is going on the future trends like biomimmetic surface coatings and drug induced surface coatings to improve the quality of the dental implants.

\section{REFERENCES}

1. Fouziya, B., Uthappa, M. A., Amara, D., Tom, N., Byrappa, S., \& Sunny, K. (2016). Surface modifications of titanium implants-The new, the old, and the never heard of options. Journal of Advanced Clinical and Research Insights, 3(6), 215-219.

2. Carlsson, L. V., Albrektsson, T., \& Berman, C. (1989). Bone response to plasma-cleaned titanium implants. International Journal of Oral \& Maxillofacial Implants, 4(3).

3. Wennerberg, A., Bolind, P., \& Albrektsson, T. (1991). Glow-discharge pretreated implants combined with temporary bone tissue ischemia. Swedish dental journal, 15(2), 95-101.

4. Cochran, D. L., Schenk, R. K., Lussi, A., Higginbottom, F. L., \& Buser, D. (1998). Bone response to unloaded and loaded titanium implants with a sandblasted and acid- etched surface: A histometric study in the canine mandible. Journal of Biomedical Materials Research: An Official Journal of The Society for Biomaterials, The Japanese Society for Biomaterials, and the Australian Society for Biomaterials, 40(1), 1-11.

5. Urban, R. M., Jacobs, J. J., Tomlinson, M. J., Gavrilovic, J., Black, J., \& Peoc'h, M. (2000). Dissemination of wear particles to the liver, spleen, and abdominal lymph nodes of patients with hip or knee replacement. JBJS, 82(4), 457.

6. Browne, M., \& Gregson, P. J. (2000). Effect of mechanical surface pretreatment on metal ion release. Biomaterials, 21(4), 385-392.

7. Martini, D., Fini, M., Franchi, M., De Pasquale, V., Bacchelli, B., Gamberini, M., ... \& Raspanti, M. (2003). Detachment of titanium and fluorohydroxyapatite particles in unloaded endosseous implants. Biomaterials, 24(7), 1309 1316.

8. Cho, S. A., \& Park, K. T. (2003). The removal torque of titanium screw inserted in rabbit tibia treated by dual acid etching. Biomaterials, 24(20), 3611-3617.

9. Park, J. Y., \& Davies, J. E. (2000). Red blood cell and platelet interactions with titanium implant surfaces. Clinical oral implants research, 11(6), 530-539.

10. Trisi, P., Lazzara, R., Rebaudi, A., Rao, W., Testori, T., \& Porter, S. S. (2003). Bone- implant contact on machined and dual acid- etched surfaces after 2 months of healing in the human maxilla. Journal of periodontology, 74(7), 945956.

11. Trisi, P., Marcato, C., \& Todisco, M. (2003). Bone-to-implant apposition with machined and MTX microtextured implant surfaces in human 
sinus grafts. International Journal of Periodontics \& Restorative Dentistry, 23(5).

12. Cochran, D. L., Buser, D., Ten Bruggenkate, C. M., Weingart, D., Taylor, T. M., Bernard, J. P., ... \& Simpson, J. P. (2002). The use of reduced healing times on ITI ${ }^{\circledR}$ implants with a sandblasted and acid- etched (SLA) surface: Early results from clinical trials on ITI® SLA implants. Clinical oral implants research, 13(2), 144-153.

13. Novaes Jr, A. B., Papalexiou, V., Grisi, M. F., Souza, S. S., Taba Jr, M., \& Kajiwara, J. K. (2004). Influence of implant microstructure on the osseointegration of immediate implants placed in periodontally infected sites: a histomorphometric study in dogs. Clinical Oral Implants Research, 15(1), 34-43.

14. Taba Jr, M., Novaes Jr, A. B., Souza, S. L., Grisi, M. F., Palioto, D. B., \& Pardini, L. C. (2003). Radiographic evaluation of dental implants with different surface treatments: an experimental study in dogs. Implant dentistry, 12(3), 252-258.
15. Ong, J. L., Carnes, D. L., \& Bessho, K. (2004). Evaluation of titanium plasma-sprayed and plasma-sprayed hydroxyapatite implants in vivo. Biomaterials, 25(19), 4601-4606.

16. Aparicio, C., Gil, F. J., Fonseca, C., Barbosa, M., \& Planell, J. A. (2003). Corrosion behaviour of commercially pure titanium shot blasted with different materials and sizes of shot particles for dental implant applications. Biomaterials, 24(2), 263-273.

17. Müeller, W. D., Gross, U., Fritz, T., Voigt, C., Fischer, P., Berger, G., \& Lange, K. P. (2003). Evaluation of the interface between bone and titanium surfaces being blasted by aluminium oxide or bioceramic particles. Clinical Oral Implants Research, 14(3), 349-356.

18. Massaro, C., Rotolo, P., De Riccardis, F., Milella, E., Napoli, A., Wieland, M., \& Brunette, D. M. (2002). Comparative investigation of the surface properties of commercial titanium dental implants. Part I: chemical composition. Journal of Materials Science: Materials in Medicine, 13(6), 535-548. 